\title{
Mental health awareness
}

Resources for everyone

A

pproximately one in five adults (19.1\%)

experienced mental illness in 2018. ${ }^{1}$ In my opinion, one of the reasons that only $43.3 \%$ of those individuals received any kind of treatment or services is the stigma surrounding mental illness. ${ }^{2}$ As information professionals, we are uniquely positioned to assist patrons with finding the information and resources they need in order to learn what mental illness is, what it is not, discover that they are not alone, and find the best treatment for their situation. Everyone suffering from mental illness needs to know that there is hope for them and that they don't need to suffer alone. When people feel that there is no hope of relief, their mental illness can become fatal through suicide.

According to the Centers for Disease Control and Prevention (CDC)'s web-based Injury Statistics Query and Reporting System (WISQARS) Leading Causes of Death Reports, in 2017 suicide was the second leading cause of death in people ages 10 to 34, and it claimed the lives of more than 6,000 people ages 15 to $24 .^{3}$ According to the Spring 2019 Report from the American College Health Association National College Health Assessment, $13.3 \%$ of students surveyed "seriously considered suicide" sometime in the last 12 months. ${ }^{4}$ Suicide is preventable. But it's only preventable if those who are struggling feel like it is acceptable and safe to share how they are feeling.

There are many organizations that aim to provide support and relief for mental illness. The organizations included here (which is far from being an exhaustive list) are doing what they can to promote awareness of mental illness and to improve the mental health of people in the United States and throughout the world.

\section{Government organizations}

- Centers for Disease Control and Prevention (CDC). CDC has concise explanations about what mental health is, and why it matters. They collect a variety of data, especially from a public health viewpoint. CDC also offers a short mental health quiz, focusing more on demystifying and debunking myths, than on diagnosing potential illnesses. Access: cdc.gov/mentalhealth.

- MedlinePlus. Sponsored by the National Library of Medicine, MedlinePlus is the premier resource for consumer-health related information. They have an entire "health topics" section devoted to mental health and behavior topics. Each of the dozens of diseases and conditions have a variety of authoritative articles (many articles are also available in Spanish or other languages, or as easy-to-read materials). Access: medlineplus. gov/mentalhealthandbehavior.html.

- Mentalhealth.gov. MentalHealth.gov is the U.S. government's one-stop shop for information about mental health. Information on the site links to other government-run sites, including the CDC, NIMH, SAMHSA, and MedlinePlus. It offers great information to help consumers understand the basics

Emily Underwood is research and instruction librarian at the Hobart and William Smith Colleges Warren Hunting Smith Library, email: underwood@hws.edu

(C) 2019 Emily Underwood 
of mental health and mental illness, as well as offering resources for those supporting people who are struggling with mental illness. There are also resources for finding professional help and phone help lines. $A C$ cess: mentalhealth.gov.

\section{MentalHealth.gov}

\section{Let's talk about it.}

- National Center for PTSD. The National Center for PTSD operates out of the U.S. Department of Veterans Affairs. In addition to general PTSD information and treatment options, the National Center for PTSD is also home to the PTSDpubs article database (formerly PILOTS), the PTSD Trials Standardized Data Repository of Clinical Trials, as well as numerous mobile apps to designed assist with treatment and self-help. Access: ptsd.va.gov.

\section{- National Institute of Health (NIH).}

$\mathrm{NIH}$ is composed of 27 institutes and centers that each have specific research specialties. While there are several institutes that focus on mental health specifically, NIH also produces resources to assist people suffering from mental health issues. They publish a monthly newsletter, NIH News in Health, that frequently contains mental health-related articles, and they also produce wellness toolkits that provide practical, concrete strategies for improving one's well-being. Access: nih.gov.

- National Institute of Mental Health (NIMH). As the primary federal agency conducting research on mental disorders, NIMH (part of the NIH), is committed to improv-

\section{$\begin{array}{ll}\text { National Institute } & \begin{array}{l}\text { ing the } \\ \text { under- } \\ \text { of Mental Health } \\ \text { stand- } \\ \text { i } \mathrm{n} \mathrm{g}\end{array}\end{array}$} and treatment of mental illnesses. Information is available about research funded by NIMH, obtaining funding for research, as well as participating in clinical trials. NIMH also is home to numerous fact sheets, topic summaries, and statistics. Access: nimh.nih.gov.

- Office on Women's Health. As part of the U.S. Department of Health and Human Services, the Office on Women's Health seeks to provide leadership at the national level to improve the health and lives of women and girls. While their focus is on all aspects of women's health, website has robust resources and articles about mental health issues and how they relate to other women's health issues. Access: womenshealth.gov/mental-health.

\section{- Substance Abuse and Mental Health} Services Administration (SAMHSA). This U.S. Department of Health and Human Services agency leads public health efforts to improve behavioral health in the United States.

$$
\begin{array}{ll}
\begin{array}{c}
\text { Substance Abuse and Mental Health } \\
\text { Services Administration }
\end{array} & \begin{array}{l}
\text { grants } \\
\text { provide } \\
\text { training } \\
\text { for mental }
\end{array}
\end{array}
$$

health practitioners, and run programs like the evidenced-based practice resource center. SAMHSA also collects statistics, primarily focusing on the prevalence of substance abuse and mental illness across the country. Access: samhsa.gov.

\section{Nonprofit organizations, general}

- Brain and Behavior Research Foundation. According to the Rand Corporation, the Brain and Behavior Research Foundation is the nation's top nongovernmental funder for mental health research. The website features information about the latest discoveries in research for mental illnesses and hosts a blog with articles about managing mental illness, stories from supporters, and more. Access: bbrfoundation.org.

- Child Mind Institute. While the Child Mind Institute focuses primarily on supporting children with mental illnesses or learning disorders and their families, they have a wealth of information that is valuable to anyone. These resources include information about different disorders or concerns, challenges that children and young people face in the classroom, strategies to help educators, and expert Q\&A. Access: childmind.org.

- Mental Health America. Formerly known as the National Mental Health Asso- 
ciation, Mental Health America runs several different programs (including \#mentalillnessfeelslike) to connect individuals with information about mental illnesses and to provide hope and support for those suffering from mental illness. They provide numerous free, confidential, anonymous screening tests, as well as information for ways people can take back control of their lives, including "DIY tools" and commonly asked questions. Access: mentalhealthamerica.net.

- Mental Health First Aid USA. One of Mental Health First Aid's goals is to make first aid for mental health as common as CPR. It is an eight-hour course that teaches skills in
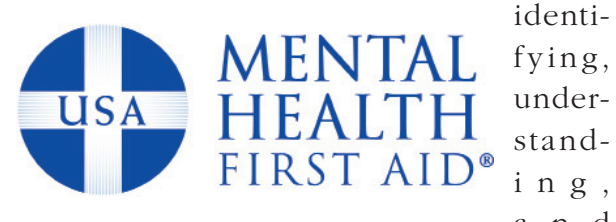

responding to signs of mental illness or substance use disorders. This program began in Australia in 2001, and has since spread to more than 25 countries. In the United States alone, more than 2 million people have been trained in mental health first aid. Courses are available in both English and Spanish. Access: mentalhealthfirstaid.org.

- National Alliance on Mental Illness (NAMI). In addition to providing information about mental conditions and treatments, NAMI has a number of infographics, fact sheets, and statistics. NAMI publishes two blogs on mental health, one of which features Q\&As with experts. NAMI also provides information for minority populations, including veterans, law enforcement officers, African Americans, Latinos, and the LGBTQ community. Access: nami.org.

\section{- National Council for Behavioral}

Health. This nonprofit organization provides support for more than 3,000 health care organizations that are providing mental health and addiction treatment and services. The National Council for Behavioral Health sponsors the Mental Health First Aid USA program, as well as a major national conference for behavioral health care. Their policy action center advocates for improved legislation surrounding mental health care. Access: thenationalcouncil.org.

\section{Nonprofit organizations, specialized}

- Active Minds. Active Minds is a suicide awareness and prevention organization that was founded by a college student after her brother completed suicide. Their website explains some of the warning signs that someone may be contemplating suicide and also provides resources to assist them. Active minds has developed a number of programs that can be implemented on college campuses to increase awareness about suicide and prevention. They also have speakers that can speak about mental health awareness and stigma reduction. Access: activeminds.org.

\section{- Anxiety and Depression Association} of America (ADAA). The ADAA provides resources for both professionals and the public related to anxiety and depression disorders. Among the resources provided for the public are personal stories, blog posts from experts,

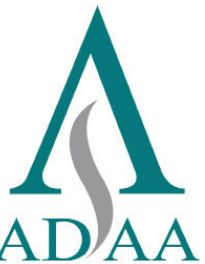

ANXIETY AND DEPRESSION ASSOCIATION OF AMERICA information about commonly co-occurring disorders, and tips for managing anxiety and stress. They also have information about clinical trials and finding treatment and support. Access: adaa.org.

- Depression and Bipolar Support Alliance (DBSA). DBSA envisions wellness for people who are living with mood disorders, including depression and bipolar disorder. In addition to general education materials about mood disorders, DBSA also shares myriad stories from people living with mood disorders. They also host online support groups, podcasts, webinars, and an online course about living successfully with a mood disorder. Access: dbsalliance.org.

\section{- National Eating Disorders Association} (NEDA). NEDA is a major nonprofit bringing awareness to eating disorders. In fall 2018, NEDA merged with the Binge Eating Disorders Association in order to provide more comprehensive 
support for all eating disorders. As part of that merger, NEDA now sponsors Weight Stigma Awareness Week each September. NEDA aims to build supportive communities for recovery by providing resources, including a phone helpline, screening tools, information about finding treatments options and support groups, research funding, and awareness events, including the Body Project. Access: nationaleatingdisorders.org.

- National Suicide Prevention Life-

line. This nationwide network of crisis centers offers free, confidential support to people in suicidal crisis or emotional distress 24

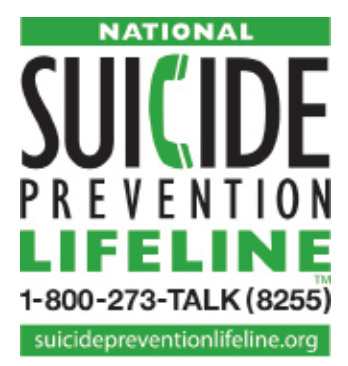
hours a day, 7 days a week. The lifeline is available both by phone and by chat and in English and Spanish and for the deaf or hard of hearing. They offer resources for a variety of communities, including veterans, LGBTQ+, attempt survivors, loss survivors, Native Americans, deaf or hard of hearing, and youth. Access: suicidepreventionlifeline. org or 1-800-273-TALK (8255).

- The Trevor Project. The Trevor Project provides crisis intervention and suicide prevention services to LGBTQ+ young people (particularly those under 25 years of age). Their resources include information about the warning signs of suicide and a support center with information and FAQs specifically geared toward the LGBTQ+ community. They also run a lifeline available by phone, chat, and text 24 hours a day, 7 days a week. Access: thetrevorproject.org.

\section{Professional organizations}

- American Psychiatric Association (APA). While many of the resources available through APA are geared toward psychiatry professionals, they do have a series of webpages devoted to "patients and families." These resources include topic pages for many illnesses complete with patient stories, topic summaries, Expert Q\&A, and relevant blog or news articles. Access: psychiatry.org.

- American Psychological Association (APA). In addition to being the organization responsible for the popular citation style, APA's website offers a wealth of information for those interested in psychology-related topics. Available topics expand beyond typical mental illnesses and include issues like shyness, trauma, learning and memory, and even parenting. Each topic includes not only related articles and resources, but also includes a scrolling display of related APA publications. Recommended books range from those with a professional audience to children's picture books. Access: apa.org.

\section{International organizations}

- World Health Organization (WHO).

WHO maintains information about mental disorders across the world. WHO has several projects they are currently working on to expand access to mental health care across the globe. The have a variety of fact sheets and data available on a number of mental disorders, including suicide. Their website is available in Arabic, Chinese, English, French, Russian, and Spanish. Access: who.int /mental_health.

\section{Notes}

1. Substance Abuse and Mental Health Services Administration, "Results from the 2018 National Survey on Drug Use and Health: Detailed Tables," https://www.samhsa.gov/data/nsduh/reports-detailed-tables -2018-NSDUH, table 8.1B.

2. Ibid., table $8.17 \mathrm{~B}$.

3. Centers for Disease Control and Prevention WISQARS, "Leading Causes of Death Reports, 1981-2017," January 18, 2019, https://webappa.cdc.gov/sasweb/ncipc /leadcause.html.

4. American College Health AssociationNational College Health Assessment, "Reference Group Executive Summary, Spring 2019," https://www.acha.org/documents / ncha/NCHA-II_SPRING_2019_US _REFERENCE_GROUP_EXECUTIVE _SUMMARY.pdf, 13. $\boldsymbol{n}$ 